\title{
O Programa Nacional da Alfabetização na Idade Certa (PNAIC) no Vale do Paranhana: 0 contexto da prática
}

\section{Resumo}

O presente artigo apresenta os resultados da pesquisa realizada na FACCAT, com apoio da FAPERGS, que visa analisar a implantação do Programa Nacional de Alfabetização na Idade Certa (PNAIC) nas redes municipais de dois municípios que compõem o Vale do Paranhana. O PNAIC é uma política pública de educação, na área da alfabetização, e apresenta como um dos seus objetivos alfabetizar todas as crianças até os oito anos de idade. Para analisar os dados, será utilizada a abordagem do ciclo de políticas. Especialmente nesta pesquisa, analisa-se o contexto da prática em que ocorre a implantação do programa.

Palavras-chave: PNAIC. Alfabetização. Anos iniciais.

\begin{abstract}
This article presents the results of the survey in FACCAT, with support from FAPERGS, which aims to analyze the implementation of the National Programme of Alphabetization in Right Age (PNAIC) in municipal networks of the two cities that compose the region Vale do Paranhana. The PNAIC is a public policy of education, in the area of alphabetization, and has as objective to alphabetize all children up to the age of eight. To analyze the data, will be used the approach of the policy cycle. Especially in this study, analyze the context of practice in the implementation of the program.
\end{abstract}

Keywords: PNAIC. Alphabetization. Early years.

\section{Introdução}

O Pacto Nacional pela Alfabetização na Idade Certa - PNAIC (BRASIL, 2013) - é uma política de continuidade do governo brasileiro voltada à formação dos educadores,

\footnotetext{
${ }^{1}$ Acadêmica do Curso de Pedagogia das Faculdades Integradas de Taquara - Faccat/RS. Bolsista FAPERGS. alinemaria94@gmail.com

${ }^{2}$ Acadêmica do Curso de Pedagogia das Faculdades Integradas de Taquara - Faccat/RS. Bolsista FAPERGS. mariaangelicadeoliveira8@gmail.com

3 Professora das Faculdades Integradas de Taquara - Faccat/RS. Doutora em Educação. rcaetano@faccat.br
} 
que começou com o Programa de Formação de Professores Alfabetizadores (Profa), criado pelo MEC, em 2001, com a proposta de orientar as ações educativas de alfabetização na Educação Infantil, no Ensino Fundamental e na Educação de Jovens e Adultos (EJA), estendendo-se, posteriormente, com o Pró-Letramento, iniciado em 2005. Estas ações configuram a atual política nacional de alfabetização, que culmina no PNAIC, aprovado pela Medida Provisória (MP) n-586/2013. Mas foi a portaria n 867 , de 4 de julho de 2012, que instituiu o PNAIC e definiu suas ações e diretrizes gerais:

Art. $1^{\circ}$ Fica instituído o Pacto Nacional pela Alfabetização na Idade Certa, pelo qual o Ministério da Educação (MEC) e as secretarias estaduais, distritais e municipais de educação reafirmam e ampliam o compromisso previsto no Decreto no 6.094 , de 24 de abril de 2007, de alfabetizar as crianças até, no máximo, os oito anos de idade, ao final do 3o ano do ensino fundamental, aferindo os resultados por exame periódico específico, que passa a abranger: I - a alfabetização em língua portuguesa e em matemática; II - a realização de avaliações anuais universais, pelo Instituto Nacional de Estudos e Pesquisas Educacionais Anísio Teixeira - INEP, para os concluintes do 3 o ano do ensino fundamental; III - o apoio gerencial dos estados, aos municípios que tenham aderido às ações do Pacto, para sua efetiva implementação.

Parágrafo único. A pactuação com cada ente federado será formalizada em instrumento próprio a ser disponibilizado pelo MEC. Parágrafo único. A pactuação referida no parágrafo único do art. 1ํ é condição para a adesão de Estados, Distrito Federal e Municípios às ações do Pacto (BRASIL, 2012).

Os municípios, ao aderiram ao programa, comprometem-se a dar suporte para que ele aconteça com sucesso, alcançando qualidade no ensino ministrado nas séries iniciais do Ensino Fundamental. É importante entendermos que as ações do Programa apoiam-se em quatro eixos de atuação:

1ㅇ - Formação Continuada de Professores Alfabetizadores: Essa formação ocorre através de um curso presencial de dois anos para os professores alfabetizadores, com carga horária de 120 horas por ano, com base no programa Pró-Letramento, cuja metodologia propõe estudos e atividades práticas. Os professores que ministram as aulas, chamados de orientadores de estudo, são também professores da rede, mas que recebem uma formação específica na universidade responsável pelo polo.

2o - Materiais Didáticos e Pedagógicos: Esse eixo é formado por um conjunto de materiais específicos para alfabetização.

3o - Avaliações: Esse eixo reúne três componentes principais: avaliações processuais, disponibilização de um sistema informatizado, no qual os professores deverão inserir os resultados da Provinha Brasil de cada criança, no início e no final do $2^{\circ}$ ano, e a aplicação, junto aos alunos concluintes do 3 ㅇ ano, de uma avaliação externa universal pelo INEP, visando aferir o nível de alfabetização alcançado ao final do ciclo, o que possibilitará às redes implementarem medidas e políticas corretivas.

4- - Gestão, Controle Social e Mobilização: O arranjo institucional proposto para gerir o Pacto é formado por quatro instâncias: I) um Comitê Gestor Nacional; II) uma coordenação institucional em cada estado; III) Coordenação Estadual; e IV) Coordenação Municipal, responsável pela implementação e monitoramento das ações na sua rede (BRASIL, 2012). 
Para que o programa ocorra, os quatro eixos precisam estar integrados, pois um completa e dá suporte ao outro.

É de incontestável importância a formação dos professores alfabetizadores, que, por sua vez, precisam contar com os materiais didáticos e pedagógicos como recursos eficazes para enriquecerem suas práticas, proporcionando aos alunos aulas prazerosas e significativas. E, para analisar os avanços e diagnosticar possíveis lacunas, são necessárias as avaliações.

A portaria $\mathrm{n}$ - 1.458 , de 14 de dezembro de 2012, foi criada para definir categorias e parâmetros para a concessão de bolsas de estudo e pesquisa no âmbito do PNAIC conforme destacamos a seguir:

Art. 1 으 - A Formação Continuada de Professores Alfabetizadores tem como objetivo apoiar todos os professores que atuam no ciclo de alfabetização, incluindo os que atuam nas turmas multisseriadas e multietapa, a planejarem as aulas e a usarem de modo articulado os materiais e as referências curriculares e pedagógicas ofertados pelo MEC às redes que aderirem ao Pacto Nacional pela Alfabetização na Idade Certa e desenvolverem as ações desse Pacto.

Art. $4^{\circ}$ - A Formação Continuada de Professores Alfabetizadores contempla o pagamento de bolsas para as seguintes funções:

I - coordenador-geral da IES;

II - coordenador-adjunto junto à IES;

III - supervisor junto à IES;

IV - formador junto à IES;

V - coordenador das ações do Pacto nos estados, Distrito Federal e municípios;

VI - orientador de estudo; e

VII - professor alfabetizador.

Para essa pesquisa, vamos nos deter na descrição das funções de coordenador municipal, orientador de estudo e professor alfabetizador.

O coordenador das ações do Pacto, nos municípios, será indicado pela respectiva secretaria de educação e deverá ser selecionado, preferencialmente, dentre aquelas pessoas que atendam às seguintes características: ser servidor efetivo da secretaria de educação; ter experiência na coordenação de projetos ou programas federais; possuir amplo conhecimento da rede de escolas, dos gestores escolares e dos docentes envolvidos no ciclo de alfabetização; ter capacidade de se comunicar com os atores locais envolvidos no ciclo de alfabetização e de mobilizá-los; e ter familiaridade com os meios de comunicação virtuais.

Os orientadores de estudo também serão escolhidos em processo de seleção pública e transparente, respeitando pré-requisitos quanto à formação e à experiência. Esses candidatos devem ter as seguintes características: ser professor efetivo da rede pública de ensino que promove a seleção; ter disponibilidade para dedicar-se ao curso e à multiplicação junto aos professores alfabetizadores; e, se possível, ter sido tutor do Programa Pró-Letramento.

Os professores alfabetizadores deverão ser todos aqueles que estiverem em exercício de docência, de 1음 a 30 ano do Ensino Fundamental de 9 anos, e, preferencialmente, membros efetivos do município referido. 


\section{Metodologia}

A metodologia de análise dos dados utilizados é a abordagem denominada "Ciclo de políticas", de Stephen Ball e Richard Bowe, sociólogos norte-americanos, referenciados pelo autor Jefferson Mainardes (2006), que realiza estudos na perspectiva das políticas educacionais. Por ser Mainardes referencial nacional dos estudos do Ciclo de Políticas em educação, cabe aqui destacar suas colaborações para nossa metodologia de análise dos dados empíricos, quando destaca a abordagem de Stephen Ball e Richard Bowe:

Essa abordagem destaca a natureza complexa e controversa da política educacional, enfatiza os processos micropolíticos e a ação dos profissionais que lidam com as políticas no nível local e indica a necessidade de se articularem os processos macro e micro na análise de políticas educacionais. É importante destacar desde o princípio que este referencial teórico analítico não é estático, mas dinâmico e flexível [...] (apud MAINARDES, 2006, p. 3).

Sendo assim, a metodologia de análise das políticas educacionais, no contexto mais amplo e também local, tendo por objetivo compreender como as políticas, são formuladas e implementadas em diferentes contextos.

Ball e Bowe, segundo Mainardes (2006), destacam a influência dos profissionais da educação nas políticas educacionais, ou seja: “[...] os profissionais que atuam nas escolas não são totalmente excluídos dos processos de formulação ou implementação de políticas [...]". Esta abordagem metodológica, segundo seus autores, deveria estar focada na

[...] formação do discurso da política e sobre a interpretação ativa que os profissionais que atuam no contexto da prática fazem para relacionar os textos da política à prática. Isso envolve identificar processos de resistência, acomodações, subterfúgios e conformismo dentro e entre as arenas da prática, e o delineamento de conflitos e disparidades entre os discursos nessas arenas (apud MAINARDES, 2006, p. 4).

Assim, os autores delimitaram sua abordagem metodológica, sendo distribuída em três contextos principais, sendo estes

[...] o contexto de influência, o contexto da produção de texto e o contexto da prática. Esses contextos estão inter-relacionados, não têm uma dimensão temporal ou sequencial e não são etapas lineares. Cada um desses contextos apresenta arenas, lugares e grupos de interesse e cada um deles envolve disputas e embates (BOWE, 1992 et al. apud MAINARDES, 2006, p. 4).

Podemos afirmar que, em cada um destes contextos, o ciclo de políticas ocorre na espera educacional, sendo esta articulação entre estes contextos nosso campo de análise. Neste texto, deter-nos-emos ao contexto da política em si, às legislações, aos documentos publicados, aos materiais do programa e ao contexto da prática, caracterizados pela análise da implantação do programa em dois municípios da região.

De acordo com Bowe et al. (1992), o contexto da prática é onde a política está sujeita à interpretação e recriação e onde a política produz efeitos e consequências que podem representar mudanças e transformações significativas na política original. Para 
estes autores, o ponto-chave é que as políticas não são simplesmente "implementadas" dentro desta arena (contexto da prática), mas estão sujeitas à interpretação e, então, a serem "recriadas":

Os profissionais que atuam no contexto da prática [escolas, por exemplo] não enfrentam os textos políticos como leitores ingênuos, eles vêm com suas histórias, experiências, valores e propósitos (...). Políticas serão interpretadas diferentemente uma vez que histórias, experiências, valores, propósitos e interesses são diversos. A questão é que os autores dos textos políticos não podem controlar os significados de seus textos. Partes podem ser rejeitadas, selecionadas, ignoradas, deliberadamente mal entendidas, réplicas podem ser superficiais etc. Além disso, interpretação é uma questão de disputa. Interpretações diferentes serão contestadas, uma vez que se relacionam com interesses diversos, uma ou outra interpretação predominará, embora desvios ou interpretações minoritárias possam ser importante. (BOWE et al., 1992, p. 22)

Esta abordagem, portanto, assume que os professores e demais profissionais exercem um papel ativo no processo de interpretação e reinterpretação das políticas educacionais, e, dessa forma, o que eles pensam e no que acreditam têm implicações no processo de implementação das políticas.

Seguindo as orientações metodológicas do ciclo de políticas, este trabalho envolve uma diversidade de procedimentos para a coleta de dados, já que analisa a política de implantação do PNAIC.

\section{Os cadernos de formação para os alfabetizadores}

Segundo os cadernos de formação, o PNAIC é um acordo formal assumido pelo Governo Federal, estados, municípios e entidades para firmar o compromisso de alfabetizar crianças até, no máximo, oito anos de idade, tendo como eixo principal a formação continuada de professores alfabetizadores, proporcionando para isso materiais didáticos de alta qualidade, incluindo dentre eles os cadernos de formação do professor. Esses cadernos formam um conjunto de materiais, o qual contém três cadernos de apresentação, sendo eles Apresentação do programa; Caderno de formação de professores; Caderno de Educação Especial e oito cadernos, um para cada ano, e para as escolas do campo, com textos teóricos sobre os temas da formação, relatos de professores, sugestões de atividades, dentre outros.

Analisando os cadernos de formação, pode-se dizer que são compostos por informações claras e objetivas sobre o que deve ser trabalhado especificamente em cada ano do ciclo de alfabetização. As unidades trazem uma sequência de títulos que aprofundam e ampliam o conhecimento do professor.

Um dos principais eixos dos cadernos de formação foi especificar o que se deve Introduzir (I); Aprofundar (A); e Consolidar (C) em cada ano, respeitando a legislação federal.

Fazendo uma análise específica dos quadros que compõem os cadernos, podese dizer que estão bem estruturados, principalmente em relação aos conhecimentos a serem trabalhados, em especial no 1 o ano, onde se entende que é necessário alfabetizar nesse ano, pois, quando se diz que se deve Introduzir, Aprofundar e Consolidar, sugere- 
se que as crianças leiam, ajustando a pauta sonora à escrita; identifiquem semelhanças sonoras em sílabas e em rimas; percebam que palavras diferentes variam quanto ao número, repertório e ordem de letras, entende-se que, as crianças necessitam ser alfabetizadas até o fim do 10 ano, pois se não estiverem alfabetizadas não será possível, Introduzir, Aprofundar e Consolidar o que se pede. Ler e escrever com autonomia, nos cadernos do PNAIC, significa ler e escrever sem precisar de ledor ou escriba, o que só é possível nos casos em que as crianças dominam o Sistema de Escrita Alfabética.

Destaca-se até aqui que o PNAIC traz claramente a intenção de alfabetizar os alunos já no primeiro ano do Ensino Fundamental, o que discutiremos nesta pesquisa, embora com limitações para este artigo.

Há de se destacar ainda que o Plano de Desenvolvimento da Educação (PDE) e o Plano Nacional de Educação (PNE) abordam o tema da alfabetização, no Decreto no 6.094 , de 24/4/2007, que define, no inciso II do art. 2으, a responsabilidade dos entes governamentais de "alfabetizar as crianças até, no máximo, os oito anos de idade, aferindo os resultados por exame periódico específico". E a Meta 5 do Plano Nacional de Educação também reforça este aspecto, ao determinar a necessidade de "alfabetizar todas as crianças até, no máximo, os oito anos de idade". Portanto é através de políticas indutivas do Ministério da Educação que o PNAIC vem acontecendo nos municípios e estados do Brasil, com conceitos e metas bem definidos para o processo de alfabetização.

\section{A implantação do PNAIC em dois municípios da região}

A pesquisa que está em andamento tem como objetivo analisar a implantação do PNAIC em dois municípios da região do Vale do Paranhana. Para tal, foram realizadas entrevistas com as coordenadoras municipais, com as orientadoras de estudos e com as professoras alfabetizadoras. Faz parte dos objetivos da pesquisa compreender como o contexto da política e da prática se relacionam nessa implantação, quais as contradições, as influências e as resistências dos envolvidos no processo. Apresentaremos, a seguir, a primeira fase de implantação do PNAIC através das entrevistas com as coordenadoras municipais.

A implantação do programa no município A, segundo avaliação da coordenadora municipal, "trouxe uma luz para a aprendizagem em geral, pois os professores possuíam muitas dúvidas em relação aos conteúdos do ciclo de alfabetização, principalmente sobre o que se trabalhar no 10 ano. O PNAIC clareou e especificou objetivamente como e o que deve ser trabalhado neste ciclo" (COORDENADORA A).

O município e a Secretaria de Educação receberam muito bem o programa, dando todo o suporte necessário para a sua implantação. Quanto à reação dos professores na implantação do programa, "foi muito boa, embora havendo algumas resistências em relação à cobrança exigida pelo programa, pois exige que metas sejam alcançadas". Alguns professores esperavam que o programa trouxesse atividades prontas e eles teriam apenas que aplicar, e não foi isso que aconteceu. Assim, os professores tiveram que se desacomodar em relação às suas práticas educativas.

Para a implantação do programa, a Secretaria de Educação veio realizando discussões com os professores, coordenadores, escolas e diretores, durante o ano anterior, 
debatendo e discutindo a possibilidade da implantação do programa no município. Os orientadores de estudo não acompanharam presencialmente, no ano de 2013, as ações do Pacto no município, porém o coordenador municipal faz relatórios mensais das suas ações e tudo o que é planejado para as formações é enviado para os orientadores, para que seja revisado e autorizado.

O critério usado pelo município, para a escolha dos orientadores, foi que eles não estivessem em sala de aula, pois necessitam se afastar mensalmente, por um período de três dias, para as formações na Universidade Federal de Pelotas (UFPEL) - universidade formadora -, e isso iria prejudicar as escolas e os alunos em geral. Também foram escoIhidos por demonstrarem anteriormente um trabalho de destaque como professores. O trabalho dos orientadores é participar das formações, planejar minuciosamente suas aulas para os professores e acompanhar (supervisionar) as práticas desenvolvidas pelo professor em sala de aula. A coordenadora municipal cita que o trabalho da equipe é muito importante e que realizam encontros semanais entre eles para organizarem e discutirem o trabalho que estão realizando. Ela afirma que "a maioria dos professores está demonstrando interesse nas formações, mas há àqueles que estão participando apenas pela bolsa". A bolsa que os professores recebem é de $\mathrm{R} \$ \mathbf{2 0 0 , 0 0}$, e as reuniões do pacto ocorrem à noite.

As alterações que o PNAIC tem trazido ao trabalho dos professores "estão sendo visivelmente notadas, através do interesse que os professores estão demonstrando ao participar das formações e apresentar suas práticas aos colegas. Há aqueles que ainda demonstram uma certa resistência em aceitar as mudanças, mas, aos poucos, espera-se que possam, com o tempo, mudar esta visão" (COORDENADORA A).

As dificuldades apresentadas com a implantação do PNAIC, segundo a coordenadora, foram "as resistências de alguns professores em relação ao novo, em terem que se desacomodar, ou seja, mudar radicalmente a sua prática educacional, e a preocupação com os alunos do 3 o ano, que não tiveram a oportunidade de participar do ciclo completo do programa" (COORDENADORA A).

Segundo a coordenadora, há uma grande preocupação com os professores contratados que estão participando do programa, sendo que já está havendo uma discussão interna, na secretaria de educação, em relação a isso, porém há uma quantidade muito pequena de professores nesta situação. E explica que "uma das ações previstas para o próximo ano é dar prioridade de contrato, caso o município necessite, a estes professores que participaram do programa".

Quando possível, há visitas da coordenadora às escolas e salas de aula, sendo que esta acompanha e troca ideias sobre o trabalho dos professores até por redes sociais. Já estão sendo discutidas internamente ações para a continuidade do programa, destacando que será avaliado o que houve de positivo e de negativo, no decorrer do ano, para possíveis ajustes, visando à possibilidade de manter o mesmo quadro de professores formadores, pois isso é uma exigência do programa.

No município B, o programa "está norteando o trabalho dos professores em sala de aula, levando um conhecimento científico de termos básicos, já conhecidos pelos professores, mas que eram deixados de lado, como os níveis de alfabetização, a sequência didática e o projeto de trabalho", conforme relato da coordenadora. Relatou ainda 
que "o termo de adesão para a participação do município no programa foi assinado pela gestão anterior, e a nova e atual gestão da Secretaria de Educação ainda tinha dúvidas de como seria o funcionamento do PNAIC, e, por isso, a Secretaria solicitou à UFPEL, que é a responsável pelas formações do polo, um auxílio, uma orientação maior quanto às leis e ao funcionamento do programa, e, a partir daí, a secretaria passou a dar todo o suporte necessário para o sucesso do programa" (COORDENADORA B).

Sobre a implantação do programa no Município, a coordenadora acredita que os primeiros passos, dados pela gestão passada, tenham sido discussões com os envolvidos no processo (Direção, Professores, Coordenadores e Orientadores); a escolha dos orientadores de estudo, obedecendo a critérios desconhecidos por ela. A Coordenadora relata ainda que, "em 2013, foi organizado o local para as formações e foi-se dando o suporte para o funcionamento do programa".

Ela também coloca que "houve resistências de alguns professores que, inclusive, negaram-se a participar do programa. Talvez por falta de interesse, ou por não terem recebido informações adequadas, embora tenham sido feitas reuniões com professores e direção, onde foi apresentado como seria o programa e como seria a formação" (COORDENADORA B).

Os orientadores de estudo do programa não acompanham diretamente as ações do PNAIC no Município, pois as reuniões da coordenação são feitas uma vez ao ano apenas, mas, mensalmente, os coordenadores fazem relatórios de suas ações e os enviam aos formadores da universidade. Por essa falta de contato, a coordenadora acompanha as orientadoras nas formações na UFPEL.

O trabalho das orientadoras de estudo é participar das formações, fazer um estudo do conteúdo e passar para as alfabetizadoras, propondo atividades para sala de aula e também atividades não presenciais (que as professoras enviam para as orientadoras), além de realizar visitas às professoras em suas escolas, acompanhando e orientando suas práticas. A Coordenadora avalia como "ótima a participação dos professores que participam na formação", mas relata que falta uma adesão maior.

As alterações que o PNAIC tem trazido são visíveis, principalmente no trabalho dos professores do 1을 ano, que estão entendendo a importância de se iniciar a alfabetização já no 10 ano, dando continuidade até o 3 ㅇano. A maior dificuldade apresentada na prática, em relação à implantação do Pacto, segundo a coordenadora, "tem sido a liberação das orientadoras de estudo para irem às formações, porque as escolas têm dificuldade em liberá-las por falta de pessoal para substituí-las". E de positivo em relação à implantação é "a própria prática das professoras alfabetizadoras, fazendo a mudança, se desacomodando" (COORDENADORA B). Conforme relatou, há uma preocupação com o grande número de professores contratados que estão participando do programa este ano e que, no ano que vem, podem sair do quadro, mas já se pensa em trabalhar, no próximo ano, de forma concomitante, a parte da alfabetização e letramento e a parte da matemática.

A coordenadora municipal finaliza reiterando que já estão sendo discutidas ações para a continuidade do programa, e que o Município vai buscar trabalhar a alfabetização e a matemática integrados, e ainda coloca que, no próximo ano, será feita a reformulação dos planos de estudos para ir adequando-os às referências do programa. 


\section{Considerações finais}

A pesquisa apresentada neste artigo ainda está em andamento, mas podemos dizer que, no contexto da prática, nos dois municípios pesquisados, há diferenças na implantação do PNAIC. Ao retomar os objetivos a que nos propusemos, reiteramos que, no contexto da prática dos municípios pesquisados, o PNAIC é reinterpretado e recriado e produz efeitos e consequências que podem representar mudanças e transformações no programa original.

O ponto-chave discutido na pesquisa é o fato de o PNAIC não ser simplesmente "implementado" no contexto da prática, mas estar sujeito à interpretação e, portanto, à "recriação" dentro dos limites e possibilidades dos participantes do programa.

\section{Referências}

BRASIL. Conselho Nacional de Educação. Portaria no 1.458, de 14 de dezembro de 2012. Define categorias e parâmetros para a concessão de bolsas de estudo e pesquisa no âmbito do Pacto Nacional pela Alfabetização na Idade Certa. Ministério da Educação. Brasília, 2012.

. Ministério da Educação. Pacto Nacional pela Alfabetização na Idade Certa: O Brasil do futuro com o começo que ele merece. Brasília, 2013.

MAINARDES. Jefferson. Abordagem do ciclo de políticas: uma contribuição para a análise de políticas educacionais. Educ. Soc., Campinas, v. 27, n. 94, p. 47-69, jan./abr. 2006. Disponível em: <http://www.cedes.unicamp.br>. Acesso em: 23 mar. 2012. 